\title{
Intermittent, ambulatory dobutamine infusions in patients with severe congestive heart failure
}

Thirteen ambulatory patients with severe congestive heart failure were treated with weekly, outpatient 48-hour infusions of dobutamine. All 13 patients had at least a $25 \%$ increase in cardiac output during initial dobutamine titration, with a corresponding improvement in systemic vascular resistance. improvement in functional class was achieved in only seven patients. Additionally, only three patients survived the 26-week study period. Although no change in ventricular ectopy was noted during the initial dobutamine infusions, six patients experienced sudden death; three other patients died of progressive heart failure and one died from pulmonary embolism. These data suggest that chronic intermittent ambulatory dobutamine infusions are only partly successful in improving symptoms and probably do not prolong survival in patients with severe congestive heart failure. Administration of this form of therapy on a clinical basis should be undertaken cautiously until safety and efficacy are demonstrated in prospective, controlled trials. (AM Heart J 1986; 112:787.)

Mark J. Krell, M.D., Eva M. Kline, R.N., Eric R. Bates, M.D., John McB. Hodgson, M.D., Lee R. Dilworth, M.D., Nathan Laufer, M.D., Robert A. Vogel, M.D., and Bertram Pitt, M.D. Ann Arbor, Mich.

Dobutamine hydrochloride is an effective parenteral inotropic agent for the acute treatment of congestive heart failure..$^{1-5}$ Although tachyphylaxis has been shown to occur with prolonged infusions, ${ }^{6,7}$ sustained improvement in functional class, left ventricular function, and exercise tolerance has been demonstrated after 72-hour infusions. ${ }^{8-11}$ Intermittent, outpatient therapy with dobutamine has recently been suggested for long-term inotropic support. ${ }^{12,13}$ In this study, 13 patients with severe congestive heart failure were treated with intermittent ambulatory outpatient 48 -hour dobutamine infusions and were then followed for up to 6 months.

\section{METHODS}

Patients. Thirteen ambulatory patients, mean age $62 \pm$ 11 years, with New York Heart Association class III or IV heart failure, were studied. Their clinical characteristics are summarized in Table I. Patients were excluded if they had surgically correctable heart disease, myocardial infarction within 3 months, an associated terminal or

From the Division of Cardiology. Department of Internal Medicine, University Hospital. University of Michigan, Ann Arbor; and Veterans Administration Medical Center.

This study was supported by a grant from the Eli Lilly Corporation. Received for publication Sept. 3. 1985; revision received Jan. 3, 1986; accepted Feb. 10, 1986.

Reprint requests: Eric R. Bates, M.D., Cardiology Section, Veterans Administration Medical Center, 2215 Fuller Rd.. Ann Arbor, MI 48105. incapacitating medical illness, exercise-induced angina pectoris, or ventricular tachycardia ( $\geq 3$ beats) on a 24-hour continuous ECG recording. This study was approved by the institutional committees on human research. Informed consent was obtained from each patient.

Study protocol. Patients were hospitalized and stabilized on standard medical therapy. Radionuclide ventriculography was then performed with a conventional gamma camera (General Electric Data, Milwaukee, Wisc.) equipped with an all-purpose high sensitivity, low-energy, parallel-hole collimator interfaced to a portable cardiac imaging computer (Medical Data Systems, Ann Arbor, Mich.). Acquisitions were periormed in the 10-degree right anterior oblique, 45-degree left anterior oblique, and left lateral projections. Global left ventricular ejection fraction was calculated using a variable region-of-interest software program.

Patients then underwent right heart catheterization with a No. $7 \mathrm{~F}$ triple-lumen pulmonary artery thermodilution catheter (American Edwards Corp., Santa Ana, Calif.). After a 30-minute stabilization period, heart rate, blood pressure, pulmonary wedge pressure, and cardiac output were measured. Dobutamine infusion was then begun at $2.5 \mu \mathrm{g} / \mathrm{kg} / \mathrm{min}$. The dose was increased to $5.0,7.5$, 10.0 , and $15.0 \mu \mathrm{g} / \mathrm{kg} / \mathrm{min}$ at 20 -minute intervals. Hemodynamic measurements were repeated at each stage.

Afterwards, a subcutaneous infusion port system (MediPort, Cormed Inc., Medina, N.Y.) was implanted in the subclavicular fossa. The tip of the catheter attached to the port was inserted via the cephalic or subrlavian vein to the 
Table I. Clinical characteristics of 13 patients with chronic congestive heart failure

\begin{tabular}{cclll}
\hline Patient no. & Age $(y r) \&$ sex & Etiology & Medications & NYHA class \\
\hline 1 & $65 \mathrm{M}$ & Ischemic & F,D,N,C & IV \\
2 & $65 \mathrm{M}$ & Ischemic & F,Al, D,H & IV \\
3 & $53 \mathrm{M}$ & Ischemic & F,N,C & III \\
4 & $67 \mathrm{M}$ & Ischemic & F,D,N,C,H & III \\
5 & $50 \mathrm{M}$ & Ischemic & F,D,Am & III \\
6 & $73 \mathrm{M}$ & Ischemic & F,D,N,C & IV \\
7 & $55 \mathrm{M}$ & Idiopathic & F,Al,D,C & III \\
8 & $85 \mathrm{M}$ & Ischemic & F,M,D,N,C & IV \\
9 & $58 \mathrm{M}$ & Ischemic & F,D,N & IV \\
10 & $67 \mathrm{M}$ & Idiopathic & F,M,D,N,H,Q & IV \\
11 & $67 \mathrm{M}$ & Idiopathic & F,N,H & IV \\
12 & $43 \mathrm{M}$ & Ischemic & F,M,D,H,Q & IV \\
13 & $58 \mathrm{M}$ & Alcoholic & F,D,N,C,Am & IV
\end{tabular}

Abbreviations: $\mathrm{Al}=$ aldactone; $\mathrm{Am}=$ amiodarone; $\mathrm{C}=$ captopril; $\mathrm{D}=$ digoxin; $\mathrm{F}=$ furosemide; $\mathrm{H}=$ hydralazine; $\mathrm{M}=$ metolazone; $\mathrm{N}=$ nitrates; NYHA $=$ New York Heart Association; $Q=$ quinidine.

Table II. Baseline hemodynamic data

\begin{tabular}{|c|c|c|c|c|c|c|}
\hline Patient no. & $\begin{array}{c}H R \\
(b p m)\end{array}$ & $\begin{array}{c}M A P \\
(m m H g)\end{array}$ & $\begin{array}{c}P W P \\
(m m H g)\end{array}$ & $\begin{array}{c}C I \\
\left(L / m / m^{2}\right)\end{array}$ & $\begin{array}{c}S V R \\
\left(\text { dynes } \cdot \mathrm{s} \cdot \mathrm{cm}^{-5}\right)\end{array}$ & $\begin{array}{c}\text { LVEF } \\
\left(\begin{array}{c}c \\
(c)\end{array}\right)\end{array}$ \\
\hline 1 & 89 & 84 & 31 & 1.6 & 1920 & 15 \\
\hline 2 & 78 & 92 & 20 & 1.5 & 2114 & 22 \\
\hline 3 & 76 & 85 & 15 & 1.8 & 1741 & 11 \\
\hline 4 & 80 & 87 & 18 & 1.8 & 1913 & 14 \\
\hline 5 & 84 & 94 & 14 & 2.3 & 1780 & 16 \\
\hline 6 & 88 & 76 & 36 & 1.7 & 2133 & 18 \\
\hline 7 & 100 & 90 & 24 & 1.5 & 1694 & 15 \\
\hline 8 & 66 & 75 & 18 & 1.2 & 2588 & 22 \\
\hline 9 & 96 & 77 & 20 & 1.5 & 2529 & 14 \\
\hline 10 & 93 & 53 & 26 & 1.8 & 752 & 27 \\
\hline 11 & 105 & 79 & 31 & 1.4 & 1675 & 15 \\
\hline 12 & 82 & 90 & 38 & 1.7 & 1882 & 17 \\
\hline 13 & 70 & 82 & 26 & 1.4 & 2304 & 10 \\
\hline
\end{tabular}

Abbreviations: $\mathrm{CI}=$ cardiac index; $\mathrm{HR}=$ heart rate $\mathrm{LVEF}=$ left ventricular ejection fraction; $\mathrm{M} \Lambda \mathrm{P}=$ mean arterial pressure; $\mathrm{PWP}=$ pulmonary wedge pressure; $\mathrm{SVR}=$ systemic vascular resistance.

junction of the right atrium and the superior vena cava. The dobutamine dose that gave the maximum cardiac output without inducing significant ventricular ectopy, a $10 \mathrm{~mm} \mathrm{Hg}$ rise in systolic blood pressure, a $10 \mathrm{bpm}$ rise in heart rate, or other side effects was chosen for intermittent chronic infusion.

Long-term follow-up. After hospital discharge, patients received weekly, 48-hour infusions of dobutamine hydrochloride diluted to a total volume of $60 \mathrm{cc}$ in normal saline. Solutions were infused via a right-angle Huber needle connected to an infusion pump (Cormed Inc., Medina, N.Y.) by standard extension tubing. Patients returned to the chronic twice weekly to have their infusions initiated and discontinued. After discontinuing the infusion, the port was flushed once with $5 \mathrm{cc}$ of heparinized saline. Further care was not required until the next infusion. No change in concurrent medications occurred during the study period.

Statistical analysis. Dobutamine titration hemody- namic data are given as mean \pm standard deviation. The paired $t$ test was used to compare each dose with the zero dose, with an exeriment-wise alpha error of $5 \%$ using the Bonferroni multiple comparison method. A $p$ value $<0.01$ was considered significant.

\section{RESULTS}

Acute hemodynamic data. Baseline hemodynamic data before dobutamine titration are detailed in Table II. The individual hemodynamic responses to a $10 \mu \mathrm{g} / \mathrm{kg} / \mathrm{min}$ infusion of dobutamine are depicted in Fig. 1 . The mean acute hemodynamic responses to dobutamine titration are summarized in Table III. Although the trend was for increasing dobutamine infusion rates to increase heart rate and mean arterial pressure and to decrease pulmonary wedge pressure, the changes were statistically insignificant. Significant improvements in cardiac index and sys- 

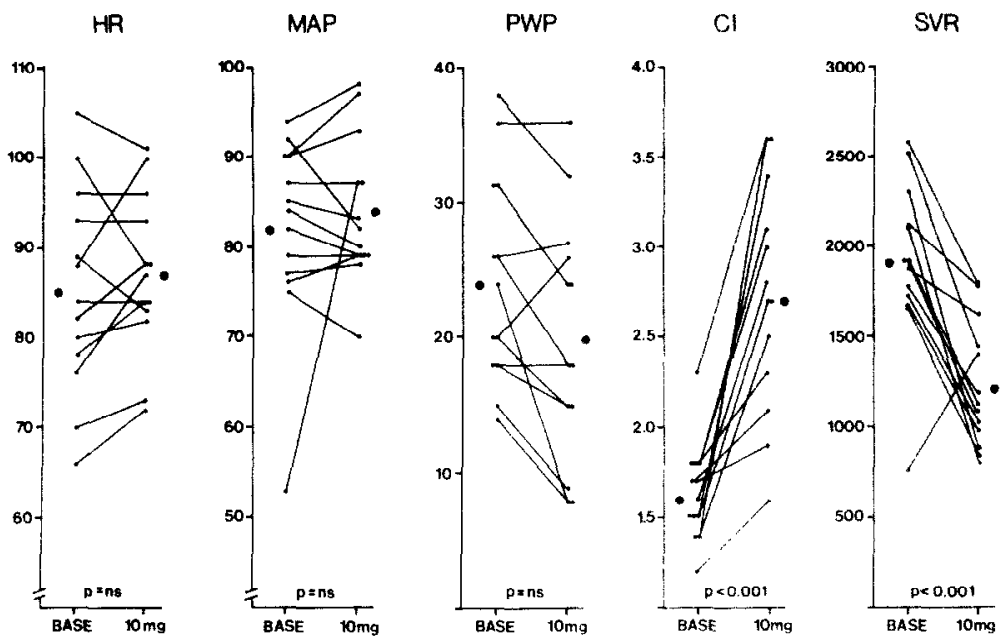

Fig. 1. Acute hemodynamic effects following dobutamine titration from baseline to $10 \mu \mathrm{g} / \mathrm{kg} / \mathrm{min}$. $C I=$ cardiac index; $H R=$ heart rate; $M A P=$ mean arterial pressure: $P W P=$ pulmonary wedge pressure; $S V R=$ systemic vascular resistance.

Table III. Hemodynamic response to dobutamine titration

\begin{tabular}{|c|c|c|c|c|c|c|}
\hline $\begin{array}{l}\text { Infusion rate } \\
(\mu g / \mathrm{kg} / \mathrm{min})\end{array}$ & No. & $\begin{array}{c}I I R \\
(b p m)\end{array}$ & $\begin{array}{c}M A P \\
(m m H g)\end{array}$ & $\begin{array}{c}P W P \\
(\mathrm{~mm} \mathrm{Hg})\end{array}$ & $\begin{array}{c}(I \\
\left(\mathrm{L} / \mathrm{m} / \mathrm{m}^{3}\right)\end{array}$ & $\begin{array}{c}s V h \\
\left(d, n e s-s \cdot \mathrm{cm}^{-4}\right)\end{array}$ \\
\hline 0 & 13 & $85 \pm 12$ & $82 \pm 11$ & $24 \pm 8$ & $1.6 \pm .3$ & $1925 \div 463$ \\
\hline 2.5 & 10 & $82 \pm 8$ & $84 \pm 7$ & $20 \pm 9$ & $2.1 \pm .4^{*}$ & $543 \pm 394^{k}$ \\
\hline 5.0 & 12 & $85 \pm 11$ & $83 \pm 7$ & $22 \pm 9$ & $2.4 \pm .67$ & $1331=418$ \\
\hline 7.5 & 9 & $86 \pm 10$ & $83 \pm 6$ & $24 \pm 8$ & $2.5+.6^{*}$ & $33: \pm 299^{*}$ \\
\hline 10.0 & 13 & $87 \pm 10$ & $84 \pm 8$ & $20 \pm 9$ & $2.7 \pm .6+$ & $214+364 t$ \\
\hline 15.0 & 10 & $92 \pm 13$ & $84 \pm 9$ & $19 \pm 8$ & $3.2 \pm .6 t$ & $0050237+$ \\
\hline
\end{tabular}

Values are mean $\pm \mathrm{SD}$.

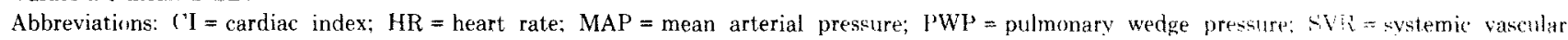
resistance.

${ }^{*} p<0.01$ vs. baseline.

$\uparrow p<0.001$ vs baseline.

temic vascular resistance were found at infusion rates $\geq 2.5 \mu \mathrm{g} / \mathrm{kg} / \mathrm{min}$. All patients achieved at least a $25 \%$ increase in cardiac output on the dose that was subsequently chosen for the chronic infusion rate. This dose averaged $7.5 \mu \mathrm{g} / \mathrm{kg} / \mathrm{min}$ for the group.

Follow-up and mortality (Table IV). Symptomatic improvement was achieved in 7 of $13(54 \%)$ patients. Four improved by one functional class, two improved by two classes, and one improved by three classes. Nevertheless, only three patients (Nos. 3, 5, and 13) survived the 26 -week study period. Two of the surviving patients were the only patients in the group treated with amiodarone. Sudden death occurred in six patients, three died of progressive heart failure, and one died from pulmonary embolism. Three of the deaths occurred during the weekly 48-hour infusion period: one patient died suddenly, while two died in cardiogenic shock.
Table IV. Functional status and survival data

\begin{tabular}{cccccc}
\multicolumn{7}{r}{ Baseline } & $\begin{array}{c}\text { Week } \\
1\end{array}$ & $\begin{array}{c}\text { Week } \\
3\end{array}$ & $\begin{array}{c}\text { Week } \\
13\end{array}$ & $\begin{array}{c}\text { Week } \\
26\end{array}$ \\
\hline \multicolumn{2}{c}{ NYHA class } \\
I & 0 & 0 & 0 & 1 & 2 \\
II & 0 & 0 & 3 & 2 & 1 \\
III & 4 & 5 & 3 & 1 & 0 \\
IV & 9 & 8 & 1 & 1 & 0 \\
Dead & 0 & 0 & 3 & 8 & 10 \\
\hline
\end{tabular}

Abbreviation: NYHA = New York Heart Asw riati th.

\section{DISCUSSION}

Standard pharmacologic treatment of chronic congestive heart failure includes diuretics, digitalis, and vasodilator agents. While new oral inotropic agents remain investigational and unavailable to most patients, ${ }^{14-16}$ encouraging reports on the use of single 72 -hour ${ }^{8-11}$ or weekly outpatient infusions ${ }^{12,13}$ 
of dobutamine to provide chronic inotropic support in heart failure patients prompted us to pursue this mode of therapy in our patients. However, the results of the present study show that although 13 of $13(100 \%)$ patients had initial hemodynamic improvement and 7 of $13(54 \%)$ patients had symptomatic improvement, eight $(62 \%)$ died within 3 months of starting therapy and 10 of $13(77 \%)$ were dead after 6 months.

One explanation for the more negative results in the present study than in those previously reported is that our patients were more hemodynamically compromised (mean ejection fraction $16 \%$, mean cardiac index $1.6 \mathrm{~L} / \mathrm{min} / \mathrm{m}^{2}$, mean pulmonary artery wedge pressure $24 \mathrm{~mm} \mathrm{Hg}$, mean systemic vascular resistance 1925 dynes $\cdot \mathrm{s} \cdot \mathrm{cm}^{-5}$ ) and thus had more severe heart failure and a worse prognosis. Patients in Unverferth's series ${ }^{9}$ had a mean ejection fraction of $25 \%$ and a mean cardiac index of $2.0 \mathrm{~L} / \mathrm{min} / \mathrm{m}^{2}: 8$ of $37(22 \%)$ patients were dead at 10 weeks, though 17 of $30(57 \%)$ patients were dead at 10 months. Only 2 of $17(12 \%)$ patients reported by Leier et al. ${ }^{12}$ were dead at 6 months, but their baseline cardiac index was $2.5 \mathrm{~L} / \mathrm{min} / \mathrm{m}^{2}$. Applefeld et al. ${ }^{13}$ successfully treated two patients for 6 months in a protocol similar to ours, but baseline cardiac indexes were 2.3 and $2.7 \mathrm{~L} / \mathrm{min} / \mathrm{m}^{2}$, and baseline pulmonary artery wedge pressures were only 8 and $13 \mathrm{~mm} \mathrm{Hg}$. Support for the suggestion that the high mortality in our patients was due to the fact that they had more severe disease than did patients in previous studies of dobutamine therapy exists in the work by Maskin et al. ${ }^{17}$ They did not find an improvement in exercise tolerance in their patients treated with dobutamine, as did Liang et al. ${ }^{11}$ and Leier et al..$^{12}$ Mean baseline cardiac index, as in our patients, was $1.6 \mathrm{~L} / \mathrm{min} / \mathrm{m}^{2}$. Similarly, Weber et al. ${ }^{18}$ have experienced a $70 \%$ mortality over 3 to 5 months in patients with severe heart failure referred to them for investigational inotropic drug therapy. Finally, it should be noted that two of the three survivors in the present study had the lowest pulmonary wedge pressures in the group.

Another possible explanation for the early mortality in our patients is that dobutamine contributed to the six sudden deaths by precipitating malignant ventricular arrhythmias. Although increased ventricular ectopy is a recognized complication of acute inotropic drug infusions, ${ }^{19},{ }^{20}$ no change in ventricular ectopy was noted during the initial dobutamine infusions in this study. Of interest in this regard is the fact that two of our three survivors were being treated with amiodarone. None of the patients who died received amiodarone therapy. While the role of antiarrhythmic therapy in reducing mortality in patients with severe heart failure is uncertain, it should be pointed out that sudden death is relatively frequent in these patients and that digitalis, or other newer inotropic agents, may increase myocardial oxygen demands and hence predispose to ventricular arrhythmias and sudden death. The relatively high mortality and incidence of sudden death reported with inotropic agents such as milrinone in patients with severe heart failure raises the possibility that to be effective, these agents will have to be administered in conjunction with antiarrhythmic therapy.

In conclusion, our data suggest that chronic intermittent ambulatory dobutamine infusions are only partly successful in improving symptoms and probably do not prolong survival in patients with severe congestive heart failure. Administration of this form of therapy on a clinical basis should be undertaken cautiously until safety and efficacy are demonstrated in prospective, controlled trials. Whether additional interventions, such as amiodarone therapy, or earlier intervention with intermittent dobutamine infusions or other inotropic agents before end-stage heart failure develops, can benefit patients with severe heart failure remains to be determined.

We thank Diane Bauer for her skillful preparation of this manuscript and Anthony Schork, Ph.D., for statistical assistance.

\section{REFERENCES}

1. Beregovich J, Bianchi C, D'Angelo R, Diaz R, Rubler S: Hemodynamic effects of a new inotropic agent (dobutamine) in chronic heart failure. Br Heart J 1975;37:629.

2. Akhtar N, Mikulic E, Cohn JN, Chaudhry MH: Hemodynamic effects of dobutamine in patients with severe heart failure. Am J Cardiol 1975;36:202.

3. Andy J, Curry C, Ali N, Mehrotra P: Cardiovascular effects of dobutamine in severe congestive heart failure. AM HEART J 1977;94:175.

4. Leier CV, Unverferth DV, Kates RE: The relationship between plasma dobutamine concentrations and cardiovascular responses in cardiac failure. Am J Med 1979;66:238.

5. Bendersky R, Chatterjee K, Parmley W, Brundage B, Ports ' $\mathrm{l}$ ': Dobutamine in chronic ischemic heart failure: Alterations in left ventricular function and coronary hemodynamics. Am $\mathrm{J}$ Cardiol 1981;48:554.

6. Unverferth DV, Blanford M, Kates RE, Leier RE, Leier CV: Tolerance to dobutamine after a 72 hour continous infusion. Am J Med 1980;69:262.

7. MacCannell KL, Giraud GD, Hamilton PL, Groves G: Hemodynamic responses to dopamine and dobutamine infusions as a function of duration of infusion. Pharmacology 1983; $26: 29$.

8. Leier CV, Webel J, Bush CA: The cardiovascular effects of the continuous infusion of dobutamine in patients with severe cardiac failure. Circulation 1977;56:468.

9. Unverferth DV, Magorien RD, Lewis RP, Leier CV: Longterm benefit of dobutamine in patients with congestive cardiomyopathy. AM HEART J 1980;100:622. 
10. Unverferth D, Magorien R, Altschuld R, Kolibush A, Lewis $\mathrm{R}$, Leier $\mathrm{C}$ : 'The hemodynamic and metabolic advantages gained by a three-day infusion of dobutamine in patients with congestive cardiomyopathy. AM HEART J 1983;106:29.

11. Liang C, Sherman L, Doherty J, Wellington K, Lee V, Hood W: Sustained improvement of cardiac function in patients with congestive heart failure after short term infusions of dobutamine. Circulation 1984;69:113.

12. Leier CV, Huss P, Lewis RP, Unverferth DV: Drug-induced conditioning in congestive heart failure. Circulation 1982; 65:1382.

13. Applefeld MA, Newman KA, Grove WR, Sutton FJ, Roffman DS, Reed WP, Linberg SE: Intermittent, continuous outpatient dobutamine infusion in the management of congestive heart failure. Am .J Cardiol 1983;51:455.

14, LeJemetel TH, Keung E, Ribner HS, Davis R, Wexler J, Blaufox MD, Sonnenblick EH: Sustained beneficial effects of oral amrinone on cardiac and renal function in patients with severe heart failure. Am J Cardiol 1980;45:123.

15. Awan NA, Evenson MK, Needham KE, Evans TO, Hermano- vich J, Taylor CR, Amsterdam E, Mason DT: Hemodynamic effects of oral pirbuterol in chronic severe :ongestive heart failure. Circulation 1981;63:96

16. Baim DS, McDowell AV, Cherniles J, Monrad ES, Parker JA Edelson J, Braunwald E, Grossman W: Evaluation of a new bipyridine inotropic agent-milrinone-..in patients with severe congestive heart failure. N Engl J Med 1983;309:748.

17. Maskin CS, Forman R, Sonnenblick BH, Frishman WH LeJemtel TH: Failure of dobutamine to increase exercise capacity despite hemodynamic improvement in severe chronic heart failure. Am J Cardiol 1983;51:177.

18. Weber KT, Andrews V, Janicki JS: Cardiotonic agents in the management of chronic cardiac failure. $A$, Hiak' of 1982 103:639.

19. Kirlin PC, Pitt B: Hemodynamic effects of intravenous: prenalterol in severe heart failure. Am rardiol 1981 47:670.

20. LeJemtel TH, Sonnenblick EH: Should the failing heart be stimulated? N Engl J Med 1984;310:1;884

\title{
The hemodynamic determinants of the isovolumic index
}

\begin{abstract}
The isovolumic index is a recently described echocardiographic parameter of left ventricular function that is calculated as the ratio between the sum of the time of isovolumic contraction and relaxation divided by the ejection time. Although the individual components of this index may be altered by heart rate and loading conditions, an analysis of the net effect of such alterations on the isovolumic index has not been undertaken. Thus, dogs were instrumented with high-fidelity micromanometers in the left ventricle, ascending aorta, and left atrium to allow determination of the individual components of the isovolumic index and calculation of the index itself. Four sets of experiments were undertaken in random order. Left atrial pacing was used to increase heart rate by approximately $10 \mathrm{bpm}$ in five steps. Preload was elevated in five stages by saline infusions which caused successive increases of 1 to $2 \mathrm{~mm} \mathrm{Hg}$ in the left ventricular end-diastolic pressure. Systolic blood pressure was lowered or raised by approximately $10 \mathrm{~mm} \mathrm{Hg}$ per stage by three progressive, steady-state infusions of nitroprusside and phenylephrine, respectively. These experiments demonstrated little change in the isovolumic index over a broad range of heart rate. Increased left ventricular end-diastolic pressure and decreased systemic pressure caused shortening of the index. Multiple regression analysis of all experiments yielded the following: isovolumic index $=0.41-0.015$ (left ventricular end-diastolic pressure) +0.004 (systolic blood pressure); $r=0.57$, standard error $=0.13, p<0.0001$. Therefore, this investigation establishes the hemodynamic determinants of the isovolumic index and provides the basis for interpretation of directional changes in response to cardiac diseases and cardioactive drugs that can alter loading conditions. (AM HEART J 1986;112:791.)
\end{abstract}

\section{G. B. John Mancini, M.D., Harold Z. Friedman, M.D., John E. Hramiec, B.A., and Scott F. DeBoe, B.S. Ann Arbor, Mich.}

From Veterans Administration Medical Center, University of Michigan Medical School.

This study was supported by the Michigan Heart Association, Lathrup Village, Michigan; and by the Veterans Administration, Washington, I).C.

Received for publication Oct. 15, 1985; revision received Jan. 13, 1986: accepted Feb. 20, 1986.

Reprint requests: $Q$, B. John Mancini, M.D. Cardiology Section, VA Medical Center, 2215 Fuller Rd., Ann Arbor, MI 48105.
The isovolumic index is a recently described echocardiographic parameter of left ventricular function. ${ }^{1}$ It is an estimate of the sum of the total time of isovolumic contraction and relaxation divided by the ejection time and can be conveniently calculated from an $\mathrm{M}$-mode echocardiogram. The rationale for studying this index stems from two lines of reasoning. First, it has long been appreciated that in the 